\title{
INVESTIGATION OF THE EFFECT OF PERCEIVED RISK and E-DISTRUST, WEBROOMING INTENTION AND WEBROOMING BEHAVIOR IN THE FRAMEWORK OF THEORY OF REASONED ACTION
}

DOI: 10.17261/Pressacademia.2021.1386

JMML- V.8-ISS.1-2021(4)-p.53-63

\section{Buket Bora Semiz}

Bilecik Seyh Edebali University, Faculty of Administrative and Economic Sciences, Business Department, Bilecik, Turkey. buket.borasemiz@bilecik.edu.tr, ORCID: 0000-0002-5440-8496

\begin{tabular}{l}
\hline Date Received: January 12, $2021 \quad$ Date Accepted: March 13, 2021 \\
\hline To cite this document \\
Semiz, B.B., (2021). Investigation of the effect of perceived risk and e-distrust, webrooming intention and webrooming behavior in the framework \\
of theory of reasoned action. Journal of Management, Marketing and Logistics (JMML), V.8(1), p.53-63. \\
Permanent link to this document: $\underline{\text { http://doi.org/10.17261/Pressacademia.2021.1386 }}$ \\
Copyright: Published by PressAcademia and limited licensed re-use rights only.
\end{tabular}

\section{ABSTRACT}

Purpose- The purpose of this study is to examine the effect of perceived risk and e-distrust on webrooming intention and webrooming behavior in the framework of the Theory of Reasoned Action.

Methodology- Data were collected from 211 participants by using the convenience sampling method via online surveys between January 15 February 15, 2021. The data obtained were analyzed by using structural equation modeling with the partial least squares method.

Findings- According to the findings, the perceived risk of online shopping and the perceived risk of online search has effect on e-distrust and edistrust has an effect on the webrooming intention and the webrooming intention has an effect on the webrooming behavior.

Conclusion- The risks that consumers perceive in terms of delivery, financial and psychological and the perceived risks arising from not understanding the quality of the product enable them to act in webrooming behavior.

Keywords: Webrooming behavior, webrooming intention, Theory of Reasoned Action, perceived risk, e-distrust JEL Codes: M30, M31, M37

\section{ALGILANAN RISK VE E-GÜVENSIZLIĞiN WEBROOMING NIYETI VE WEBROOMING DAVRANIŞI ÜZERINDEKi ETKISININ GEREKÇELI EYLEM TEORISI ÇERÇEVESINDE INCELENMESI}

\section{ÖZET}

Amaç - Bu çalışmanın amacı, algılanan risk ve e- güvensizliğin, webrooming niyeti ve webrooming davranışı üzerindeki etkilerini gerekçeli eylem teorisi çerçevesinde incelemektir.

Yöntem- 15 Ocak-15 Şubat 2021 tarihleri arasında çevrimiçi anketler vasıtasıyla kolayda örnekleme yöntemi ile 211 katılımcıdan veri toplanmıştır. Elde edilen veriler en küçük kısmi kareler yöntemi ile yapısal eşitlik modellemesi kullanılarak analiz edilmiştir.

Bulgular- Araştırmanın bulgularına göre, çevrimiçi alışverişin algılanan riski ve çevrimiçi bilgi aramanın algılanan riskinin e- güvensizlik üzerinde etkili olduğu; e-güvensizliğin ise webrooming niyeti üzerinde etkili olduğu ve webrooming niyetinin de webrooming davranışı üzerinde etkili olduğu sonucuna ulaşılmıştır.

Sonuç- Tüketicilerin teslimat, finansal ve psikolojik olarak algıladıkları riskler ile ürünün kalitesini anlayamamaktan kaynaklanan algıladıkları riskler webrooming davranışında bulunmalarını sağlamaktadır.

Anahtar Kelimeler: Webrooming davranışı, webrooming niyeti, Gerekçeli Eylem Teorisi, algılanan risk, e-güvensizlik. JEL Kodları: M30, M31, M37 


\section{GiRiş}

Günümüzde artan müşteri taleplerini karşılamak ve rekabette geri kalmamak için kanal farklılaştırmasına giden işletmeler bir çok kanaldan tüketiciye ulaşmaya çalışmaktadır. Tüketiciler de bu farklı kanalları alışverişlerinden sağladıkları faydayı maksimize edecek şekilde değerlendirmektedirler. Webrooming davranışı da tüketicilerin istek ve ihtiyaçlarının ortaya çıkmasından başlayarak satın alma sürecini sonlandırmasına kadar geçen süreçte hem çevrimiçi hem de çevrimdışı kanalları birarada kullandığı davranış biçimlerinden biridir. Deloitte (2014) raporuna göre, tüketicilerin \%49'u satın alacakları ürünü mağazaya gitmeden önce internetten araştırmaktadır. Yine aynı raporda, elektronik ürünler ve ev eşyası gibi ürünlerde satın alacakları ürünü bilerek mağazalara giden tüketicilerin sayısının alacakları ürünü mağaza gezerek seçen ve geleneksel kanallardan bilgi toplayan tüketicilerin sayısını geçtiği ifade edilmiştir. Deloitte (2017) raporuna göre ise, tüketicilerin \%69'u Şükran Günü alışverişleri boyunca webrooming davranışı sergilemişlerdir. Tüketicileri webrooming yapmaya iten çeşitli sebepler vardır. Çevrimiçi alışverişin çevrimdışı alışverişe göre daha fazla risk algısı barındırması da bunlardan biridir. Risk algısı arttıkça da çevrimiçi alışverişe duyulan güven duygusu da azalmakta olup güvensizlik ortaya çıkmaktadır. Ortaya çıkan bu güvensizlik durumu tüketicileri her ne kadar bilgi arama davranışını internetten gerçekleştirseler de satın almayı fiziksel olarak noktalamaları ile sonuçlandırmaktadır.

Davranışların açıklanmasında niyetin önemli bir belirleyici olduğunu savunan Gerekçeli Eylem Teorisi (Theory of Reasoned ActionTRA) pazarlama alanında birçok araştırmada kullanılmaktadır. Tüketicilerin bir konu veya olguya ait tutumlarının davranışsal niyetlerini, davranışsal niyetlerinin ise gerçek davranışlarını nasıl etkilediğini anlama noktasında önemli bir teoridir. Bu çalışmada da tüketicilerin çevrimiçi alışverişe yönelik algıladıkları riskin ve güvensizliğin onları webrooming yapma niyeti göstermelerine ve akabinde de bunu davranışa çevirmelerine yönelik olarak bu teoriden faydanılmıştır. Dolayısıyla bu çalışmanın amacı, çevrimiçi alışverişlerde algılanan riskin e-güvensizlik üzerindeki etkisini ve e-güvensizliğin de Gerekçeli Eylem Teorisi bağlamında webrooming niyet ve davranışı üzerindeki etkilerini araştırmaktır. Uluslararası literatür bağlamında çok sayıda webrooming davranışına yönelik çalışma vardır. Ancak Türkçe literatürde söz konusu konu hakkında daha sınırlı bir literatür mevcuttur. Dolayısıyla bu çalışmanın literatürdeki bu boşluğa katkı sağlayacağı düşünülmektedir.

Çalışmada öncelikle araştırma modelindeki değişkenlerin yapı geçerliliği kapsamında birleşme gerçerliliğini ve ayırt edici geçerliliğini sağlayıp sağlamadığına bakılmıştir. Ayrıca araştırmada kullanılan ölçeklerin güvenilir olup olmadıklarına dair içsel tutarlııklarına da bakılmıştır. Ardından da araştırma modeli en küçük kısmi kareler yöntemi temeline dayanan SmartPLS paket programı ile test edilmiştir.

\section{TEORIK ARKA PLAN}

\subsection{Değişkenlerin Tanımlanması ve Hipotezlerin Oluşturulması}

Bauer (1960) tarafından ilk olarak ortaya atılan algılanan risk kavramı pazarlama literatüründe tüketicilerin satın alma davranışlarına etki eden önemli faktörlerden biri olarak incelenmektedir (Taylor, 1974). Çevrimiçi alışverişlerde algılanan risk, tüketicilerin internet alışverişlerinde kaybetme beklentisini sübjektif olarak değerlendirmesidir (Forsythe ve Shi, 2003). Algılanan risk, hem çevrimiçi hem de fiziksel (offline) ortamlarda tüketicilerin satın alma kararlarını etkilemektedir (Chou vd., 2016; Arora ve Sahney, 2018). Ancak, tüketiciler daha çok dokunma isteği ve satış elemanlarıyla yüz yüze iletişim eksikliği sebeplerinden (Tan ve Sutherland, 2004; Ha ve Stoel, 2009) dolayı çevrimiçi alışverişlerde geleneksel alışverişlere kıyasla daha yüksek düzeyde risk algılamaktadır (Tan, 1999; Lee \& Tan, 2003; Forsythe et al., 2006; Kim vd., 2008). Dolayısıyla algılanan risk çevrimiçi alışverişin önündeki en temel engellerden biridir (Bhatnagar vd., 2000). Birçok çalışma algılanan riski çok boyutlu olarak ölçmektedir. Bu çalışmada da çevrimiçi alışveriş riski ve çevrimiçi bilgi arama riski olarak iki boyutlu olarak ölçülmüştür. Choi ve Yang (2016), algılanan çevrimiçi bilgi aramanın riskini web sitelerinde araştırılan ürünün kalitesini anlama zorluğu olarak tanımlamıştır. Yazarlar çevrimiçi algılanan alışveriş riskini ise, psikolojik, finansal ve teslimat konusundaki riskler olarak değerlendirmişlerdir.

Çevrimiçi alışverişlerde algılanan riskin negatif etkisine karşın güven ise pozitif etkiye sahiptir (Uygun vd., 2011). Algılanan risk ne kadar yüksek olursa çevrimiçi satıcıya olan güven o kadar düşük olur (Olivero ve Lunt, 2004; Hong ve Cha, 2013). Ancak McKnight vd. (2004) ise, müşterilerin internetten alışveriş yapmasını engelleyen şeyin güvenden çok "güven eksikliği" olduğunu savunmaktadır. Güven eksikliği veya güvensizlik, güvenin yokluğu olarak değil, çevrimiçi satıcının müşterinin güvenliğini ihlal edecek şekilde davranacağı yönündeki olumsuz beklentidir (Kramer, 1999). Dolayısıyla güvensizlik, tüketicilerin mevcut çıkarlarını koruyarak savunmasızlığını ve mevcut belirsizliğini azaltmaya yönelik kararlar almasına neden olur (Lewicki, 2006). Chang ve Fang (2013)'a göre, güvensizliğin yarattığı algılanan risk güvenin varlığından daha yüksektir. Böylece müşteri güvensizliği düşük olduğunda, çevrimiçi bir satın almaya daha istekli olacaktır. 
Günümüzde tüketiciler, alışveriş maliyetlerini en aza indirmek ve alışverişten sağlayacakları potansiyel faydayı en üst düzeye çıkarmak için hem çevrimiçi hem de çevrimdışı kanalları birleştirmektedir (Gensler vd., 2012). Bütünleşik kanallı perakendecilik (omni-channel) olarak adlandırılan bu sistem tüketicilerin fiziksel bir mağazayı, çevrimiçi bir mağazayı ve hatta mobil bir mağazayı aynı anda araştırmalarını sağlayabilmektedir (Brynjolfsson, vd., 2013). Böylece ortaya showrooming ve webrooming adı verilen davranış biçimleri çıkmaktadır. Showrooming, tüketicilerin bir ürünü mağazada araştırıp internetten satın alması (Bosman,2011), webrooming ise tüketicilerin bir ürünü satın almadan önce internetten araştırma yapıp fiziksel bir mağazadan satın almasıdır (Flavian vd., 2016). Showrooming davranışı kanallar arasında yaygın bir trend olarak görülmesine rağmen bir çok araştırma internetin bilgi kaynağı olarak tercih edildiğini ancak satın almanın fiziksel ortamlarda gerçekleştiğini ifade etmektedir (Gupta vd., 2004; Dholakia vd., 2010; Verhoef vd., 2007; Fernández vd., 2018). Webrooming davranışı ile tüketiciler alışverişe yönelik riski azaltarak, internetin bilgi sağlama avantajından faydalanmaktadır (Schröder ve Zaharia, 2008; Flavian vd., 2016).

Aw vd. (2021), e-ticaretin oldukça geliştiği günümüzde çevrimiçi alışveriş yapmak varken neden tüketicilerin hala mağazalardan alışveriş yaptıkları sorusuna cevap bulabilmek için yaptıkları çalışmada webrooming davranışının tüketici kaynaklı ve kanal kaynaklı faktörlerden etkilendiğini ortaya koymuşlardır. Tüketiciden kaynaklı faktörler ürünlere dokunma isteği, fiyat karşılaştırması yapma ve satış elemanları ile iletişime girme isteğidir. Kanal kaynaklı faktörler ise çevrimiçi araştırma kolaylığı, çevrimiçi alışverişin algılanan faydası, satış personelinin algılanan yardımseverliği, çevrimiçi alışverişin algılanan riskidir. Luna (2014) ise tüketicilerin kargo ücreti ödemek istememek ve satın alınan ürünü hemen teslim alabilmek için webrooming davranışını sergilediklerini ifade etmiştir. Balasubramanian vd. (2005)'ne göre ise, tüketici algıladığı riskin yüksekliğinden, çevrimiçi kanallarda bilgi aramanın düşük maliyetinden ve satın aldığı ürünü hızlı bir şekilde elde etme isteğinden dolayı webrooming davranışına yönelmektedir. Flavian vd. (2016)'ne göre de, webrooming davranışı var olan bilginin tüketiciye daha bilinçli kararlar verdirmesini sağlamakla çevrimiçi alışveriş riski algısını da azaltmaktadır. Wolny ve Charoensuksai (2014)'de webrooming davranışını tüketicinin ilk ürün seçimini gerçekleştirdikten sonra göstereceğini ve internetin satın alma öncesinde ürün ve fiyatların karşılaştırılması noktasında vitrin görevi gördüğünü ve sonuç olarak tüketicinin nihai satın alma kararını mağazada tamamlayacağını ifade etmişlerdir. Fernandez vd. (2018) ise, tüketicilerin ürünlerin özellikleri ve fiyatlarını internetten araştırdıktan sonra mağazalardan daha planlı alışverişler yaptıkları sonucuna ulaşmışlardır.

Aw (2019) webrooming niyetini etkileyen faktörleri incelendiği çalışmada tüketicilerin alışveriş motivasyonları bağlamında verimli alışveriş ve pazarlık etme isteğinin webrooming niyetini negatif yönde etkilediğini; tüketicilerin kanal algıları bağlamında ise ürünlere hemen sahip olma isteğinin webrooming niyetini pozitif yönde etkilediğini, çevrimdışı satın alma çabası ve düşük fiyat beklentisinin ise webrooming niyetini negatif yönde etkilediğini ortaya koymuştur. Manss vd. (2020)'ne göre ise, bir perakendecinin satış sonrası hizmetleri ve fiyatlarının seviyesi webrooming davranışını tahmin eden en güçlü unsurlardır. Aw (2020)'ın bir başka çalışmasında ise ürün ilgilenimi, ürün kategorisi, dokunma isteği, satış elemanı ile iletişim isteği ve çevrimiçi yorumların algılanan faydasının webrooming niyeti üzerinde etkisi olduğu sonucuna varılmıştır. Yüzyüze iletişim eksikliği ve dokunma eksikliğine karşın fiziksel mağazaların çevrimiçi mağazalara tercih edilmesinin bir diğer sebebi de fiziksel mağazaların müşterilere sunduğu sosyal ortamlardır (Hassanein ve Head, 2005; Hassanein vd., 2009; Ogonowski vd., 2014). Yani bir başka deyişle, aslında webrooming davranışını gerçekleştiren bir çok tüketici de sosyalleşmek için çevrimdışı alışverişi çevrimiçi alışverişe tercih etmektedir.

Gerekçeli Eylem Teorisi, Fishbein ve Ajzen (1975) tarafından ortaya atılan, kişilerin bir şeye karşı geliştirdikleri tutumlarının niyetlerini, niyetlerinin de davranışlarını etkilediğini ifade eden sosyal psikoloji temelli bir teoridir. Birçok disiplinde olduğu gibi tüketici davranışları disiplininde de sıklıkla tüketicilerin satın alma niyetlerini ve davranışlarını anlamada kullanılmaktadır. Gerekçeli Eylem Teorisi'nin varsayımı bireylerin alternatif davranışların sonuçlarını bilinçli olarak göz önüne alarak alternatifler içinden en arzu edilen davranışı gerçekleştirmeleridir (Akıncı ve Kıymalıoğlu, 2014). Gerekçeli eylem teorisinin önemli bir değişkeni olan davranışsal niyet, belirli bir eyleme yönelik kararlardır (Fishbein ve Ajzen, 1975). Ajzen ve Fishbein (1980), davranışsal niyeti birçok unsurun etkilediğinden bahsederek niyet ile davranış arasındaki ilişkiyi hedef, içerik, zaman ve eyleme uygun davranışsal ölçütlerle niyetin ölçülmesi gerektiğini ve davranışın gözlemlenmesinden önce niyetin değişmeyeceği şeklinde açıklamışlardır. Gerekçeli Eylem Teorisi sonradan Ajzen (1991) tarafından Planlı Davranış Teorisi olarak geliştirilerek davranışsal kontrolün de davranışsal niyet ve gerçekleşen davranış üzerindeki etkisi ortaya koyulmuştur.

Arora ve Sahney (2016), webrooming davranışını Planlı Davranış Teorisi bağlamında incelemişlerdir. Algılanan riskin webroominge yönelik tutumlara etkisinde güven eksikliğinin aracı rolünün olduğunu, tutumların webrooming niyetini, niyetin de webrooming davranışını etkilediğini ortaya koymuşlardır. Yazarların bir başka çalışmasında ise algılanan çevrimiçi risklerin e-güvensizlik üzerinde doğrudan etkisi olduğunu ifade etmişlerdir (Arora ve Sahney, 2018). Chou vd. (2016) yapmış oldukları çalışmada webroominge yönelik niyeti itme-çekme- bağlama (pull-push-mooring) stratejileri çerçevesinde ele alarak algılanan riskin egüvensizlik üzerindeki etkisini itme stratejisi bağlamında değerlendirmişlerdir. Shankar ve Jain (2021), lüks ürünlerin hedonik ve 
faydacı değerleri ile webrooming niyeti arasında algılanan riskin düzenleyici etkisi olduğunu ifade etmişlerdir. Tüm bu bilgiler ışı̆̆ında araştırmanın hipotezleri şu şekilde ifade edilebilir:

$\mathrm{H}_{1 \mathrm{a}}$ : Çevrimiçi bilgi aramanın algılanan riskinin e-güvensizlik üzerinde pozitif etkisi vardır.

$\mathrm{H}_{1 \mathrm{~b}}$ : Çevrimiçi alışverişin algılanan riskinin e-güvensizlik üzerinde pozitif etkisi vardır.

$\mathrm{H}_{2}$ : e-Güvensizliğin webrooming niyeti üzerinde pozitif etkisi vardır.

$\mathrm{H}_{3}$ : Webrooming niyetinin webrooming davranışı üzerinde pozitif etkisi vardır.

\section{ARAŞTIRMANIN YÖNTEMI}

Bu araştırma değişkenler arasındaki ilişkileri araştırdığından neden-sonuç ilişkisine dayalı bir araştırma türündedir. Veriler çevrimiçi anketler vasıtasıyla 15 Ocak- 15 Şubat 2021 tarihleri arasında kolayda örnekleme yöntemi ile 211 katılımcıdan toplanmıştır. Bilecik Şeyh Edebali Üniversitesi Etik Kurulu Başkanlığı'ndan 08.02.2021 tarihli E-54674167-050.01.04-4978 belge numaralı etik kurul onayı araştırmada kullanılan anket formu için alınmıştır. Araştırmada kullanılan ölçekler ise şöyledir: çevrimiçi alışverişin algılanan riski ve çevrimiçi bilgi aramanın algılanan riski Choi ve Yang (2016)'ın çalışmasından, e-güvensizlik ölçeği Lee ve Turban (2011)'nın çalışmasından, webrooming niyeti ölçeği Bauer vd. (2005)'nin çalışmasından ve webrooming davranışı ölçeği ise Arora ve Sahney (2018)'in çalışmasından uyarlanmıştır. Tüm değişkenler 5'li Likert tipi ölçekle (1: Kesinlikle Katılmıyorum,5: Kesinlikle Katılıyorum) üçer madde ile ölçülmüştür. Araştırma bulguları yapısal eşitlik modellemesi ile test edilerek analizlerin yapılmasında SmartPLS programı kullanılmıştır. Araştırmada kullanılan anket formu sahaya sürülmeden önce 20 kişi ile pilot bir uygulama yapılmıştır. Bu pilot uygulama sonucunda anketteki anlaşılmayan yerler revize edilmiştir. Araştırma modeli Şekil 1'deki gibi olup, hipotezler ise aşağıdaki gibidir.

\section{Şekil 1: Araştırma Modeli}

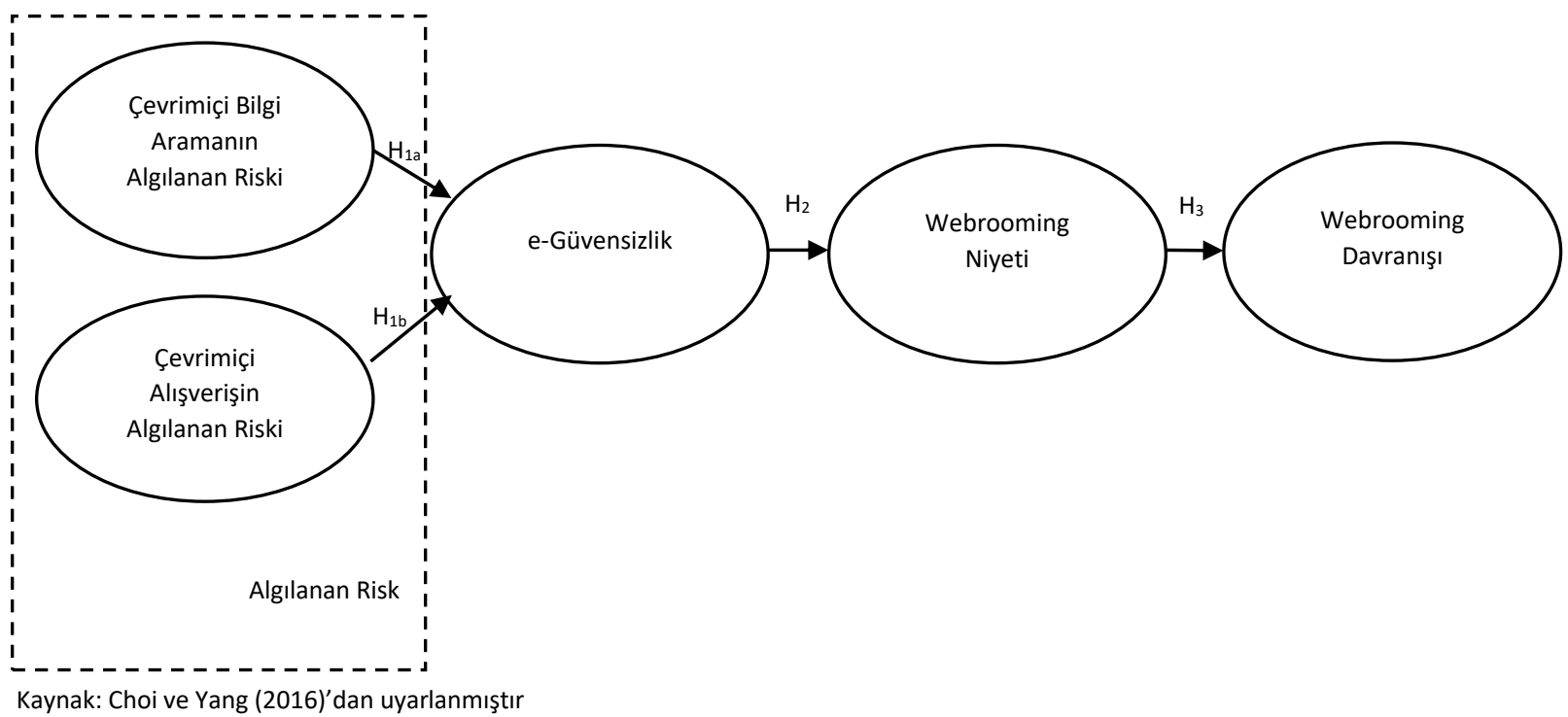

\section{VERI ANALIZi}

Veri analizi kısmında öncelikli olarak katılımcıların demografik özelliklerine dair bulgulara yer verilmiştir. Sonrasında ise araştırmada kullanılan ölçeklerin geçerlilik ve güvenilirlik analizleri yapılmıştır. Son olarak da araştırma modeli SmartPLS paket programı ile test edilmiştir.

\subsection{Demografik Özellikler}

Araştırmaya katılan katılımcıların demografik özellikleri Tablo 1'de verilmiştir. Buna göre, katılımcıların yaklaşık \%56'sı kadınlardan, \%53,1'i ise bekârlardan oluşmaktadır. Yaş açısından bakıldığında ise katılımcıların \%36'sının 21-30 yaş aralığında olduğu 
görülmektedir. Eğitim düzeyi açısından araştırmaya daha çok lisans mezunları $(\% 42,2)$ katılmıştır. Katılımcıların meslekleri değerlendirildiğinde en çok öğrencilerin olduğu, ortalama aylık aile geliri açısından da 2500 TL ve altı gelire sahip tüketicilerin araştırmaya katıldığı görülmektedir.

Tablo 1: Katılımcıların Demografik Özellikleri

\begin{tabular}{|c|c|c|c|c|c|}
\hline Cinsiyet & $f$ & $\%$ & Eğitim Düzeyi & $f$ & $\%$ \\
\hline Kadın & 118 & 55,9 & Lise ve altı & 30 & 14,2 \\
\hline Erkek & 93 & 44,1 & Ön Lisans & 47 & 22,3 \\
\hline Yaş & $f$ & $\%$ & Lisans & 89 & 42,2 \\
\hline 20 ve altı & 58 & 27,5 & Lisansüstü & 45 & 21,3 \\
\hline $21-30$ & 76 & 36,0 & Meslek & $f$ & $\%$ \\
\hline $31-40$ & 38 & 18,0 & İşçi & 15 & 7,1 \\
\hline $41-50$ & 29 & 13,7 & Memur & 18 & 8,5 \\
\hline 51 ve üstü & 10 & 4,8 & Esnaf/Tüccar & 5 & 2,4 \\
\hline Ort. Aylık Gelir & $f$ & $\%$ & Serbest Meslek & 12 & 5,7 \\
\hline 2500 TL ve altı & 64 & 30,3 & Öğrenci & 67 & 31,7 \\
\hline $2501-4500 \mathrm{TL}$ & 56 & 26,5 & Ev Hanımı & 43 & 20,4 \\
\hline $4501-6500 \mathrm{TL}$ & 37 & 17,5 & Diğer & 51 & 24,2 \\
\hline $6501-8500 \mathrm{TL}$ & 28 & 13,3 & Medeni Durum & $f$ & $\%$ \\
\hline \multirow[t]{2}{*}{8501 TL ve üstü } & 26 & 12,4 & Evli & 99 & 46,9 \\
\hline & & & Bekâr & 112 & 53,1 \\
\hline
\end{tabular}

\subsection{Geçerlilik ve Güvenilirlik Analizleri}

Araştırma modelini test etmeden önce modeldeki değişkenlerin geçerlilik ve güvenilirlik analizleri yapılmıştır. Tablo 2 'de araştırmada kullanılan ölçeklerin geçerliliklerine ve güvenilirliklerine ilişkin bilgiler yer almaktadır. Tüm ölçeklere ait faktör yükleri eşik değer olan 0,708'in üzerindedir. Cronbach Alpha katsayıları ise eşik değer olan 0,7'nin üzerinde olup 0,831-0,945 arasında değişmektedir. Ayrıca yapıları temsil eden birleşik güvenirlik katsayısı CR (Composite Reliability) değerleri de yine eşik değer olan 0,7’nin üzerinde olduğundan ölçeklerin içsel tutarlılıklarının, bir başka deyişle güvenilirliklerinin sağlandığını söylemek mümkündür (Hair vd., 2014; Henseler vd., 2016).

\section{Tablo 2: Doğrulayıcı Faktör Analizi}

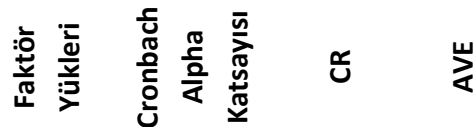

\section{Webrooming Davranışı (DVR)}

DVR2. Son birkaç alışverişimde, mağazadan alışveriş yapmadan önce ürünler ilgili $\quad 0,951$ bilgileri internetten kontrol ettim.

DVR3. Mağazadan alışveriş yapmadan önce satın alacağım ürünle ilgili internetten $\quad 0,948$ bilgi toplayarak emin olurum.

DVR1. Mağazadan bir ürün satın almadan önce internetten ürünle ilgili bilgi 0,927 topluyorum.

\section{Webrooming Niyeti (NYT)}

NYT2. İnternetten araştırıp/beğenip mağazadan ürün satın almayı düşünüyorum. NYT3. İnternetten araştırıp/beğenip mağazadan ürün satın alacağım.

NYT1. Web sitesinde ürünlere dokunup inceleyememek risklidir.

$0,945 \quad 0,945 \quad 0,964 \quad 0,900$

\section{Çevrimiçi Alışverişin Algılanan Riski (OAR)}


OAR1. İnternetten ürün satın aldığımda, kişisel bilgilerimin gizli tutulacağına 0,905 inanmıyorum.

OAR2.İnternetten ürün satın aldığımda, kredi kartı numaramın güvende olacağına $\quad 0,903$ inanmiyorum.

$0,831 \quad 0,897 \quad 0,745$

OAR3. Internetten ürün satın aldığımda, kargo ve taşıma için ödeme yapmak beni $\quad 0,776$

rahatsız ediyor.

Çevrimiçi Bilgi Aramanın Algılanan Riski (OBAR)

OBAR1. Web sitesinde gerçek ürünü inceleyememek risklidir.

OBAR2. Web sitesinde ürünlere dokunup inceleyememek risklidir.

0,955

OBAR3. Web sitesinde ürünün kalitesini anlayabilmek çok zordur.

0,936

$0,935 \quad 0,958 \quad 0,885$

e-Güvensizlik (e-GVNSZ)

e-GVNSZ2. İnternetten alışverişin güvenilir olmadığını düşünüyorum.

e-GVNSZ1. Çok fazla belirsizlik barındırdığı için bence internetten alışverişe 0,866 güvenilemez.

e-GVNSZ3. Genel olarak, internet satıcılarının verdikleri sözü tutacağına 0,860

güvenemiyorum.

Ölçeklerin geçerliliğinin test edilmesi içinde yapı geçerliliklerine bakılması gerekmektedir. Yapı geçerliliği birleşme geçerliliği ve ayırt edici geçerlilikten meydana gelmektedir. Birleşme geçerliliği için ortalama açıklanan varyans değeri olan AVE (Average Variance Extracted) değerinin 0,5'ten büyük ve CR değerinin de 0,7'den büyük ve CR değerlerinin de AVE değerlerinden büyük olması gerekmektedir (Fornell ve Larcker, 1981). Tabloya bakıldığında bu üç şartın da sağlandığını görmek mümkündür. Dolayısıyla ölçeklerin birleşme geçerliliği sağlanmıştır.

Tablo 3: Fornell ve Larcker Kriterine Göre Ayırt Edici Geçerlilik

\begin{tabular}{cccccc}
\hline & DVR & NYT & OAR & OBAR & e-GVNSZ \\
\hline DVR & $\mathbf{0 , 9 4 2}$ & & & & \\
\hline NYT & 0,546 & $\mathbf{0 , 9 4 9}$ & & & \\
\hline OAR & 0,460 & 0,450 & $\mathbf{0 , 8 6 3}$ & & \\
\hline OBAR & 0,508 & 0,504 & 0,678 & $\mathbf{0 , 9 4 1}$ & \\
\hline e-GVNSZ & 0,111 & 0,379 & 0,594 & 0,571 & $\mathbf{0 , 8 8 1}$ \\
\hline
\end{tabular}

Ayırt edici geçerlilik ise üç aşamalıdır. Bunlardan ilki Fornell ve Larcker kriterinin sağlanmasıdır. Fornell ve Larcker kriterine ilişkin bilgiler Tablo 3'te yer almaktadır. Çaprazda koyu renkle belirtilen rakamlar AVE değerlerinin karekökleridir. Diğer değeler ise değişkenlerin birbirleriyle olan korelasyon katsayılarıdır. Bu kriterin sağlanabilmesi için değişkenlerin birbirleriyle olan korelasyon katsayılarının o yapının AVE değerinden küçük olması gerekmektedir (Fornell ve Larcker, 1981; Compeau ve Higgins, 1995). Tablo 3 incelendiğinde bu koşulun sağlandığı görülmektedir.

Tablo 4: Faktör Yükleri ve Çapraz Yükler

\begin{tabular}{cccccc}
\hline & DVR & NYT & OAR & OBAR & e-GVNSZ \\
\hline DVR1 & $\mathbf{0 , 9 2 7}$ & 0,503 & 0,448 & 0,455 & 0,118 \\
\hline DVR2 & $\mathbf{0 , 9 5 1}$ & 0,549 & 0,420 & 0,511 & 0,116 \\
\hline DVR3 & $\mathbf{0 , 9 4 8}$ & 0,489 & 0,432 & 0,468 & 0,078 \\
\hline NYT1 & 0,526 & $\mathbf{0 , 9 3 7}$ & 0,461 & 0,539 & 0,437 \\
\hline NYT2 & 0,513 & $\mathbf{0 , 9 6 4}$ & 0,375 & 0,410 & 0,305 \\
\hline NYT3 & 0,515 & $\mathbf{0 , 9 4 5}$ & 0,439 & 0,476 & 0,325 \\
\hline OAR1 & 0,374 & 0,393 & $\mathbf{0 , 9 0 5}$ & 0,602 & 0,592 \\
\hline OAR2 & 0,370 & 0,355 & $\mathbf{0 , 9 0 3}$ & 0,548 & 0,545 \\
\hline OAR3 & 0,495 & 0,451 & $\mathbf{0 , 7 7 6}$ & 0,643 & 0,357 \\
\hline OBAR1 & 0,486 & 0,495 & 0,646 & $\mathbf{0 , 9 5 5}$ & 0,529 \\
\hline OBAR2 & 0,406 & 0,421 & 0,604 & $\mathbf{0 , 9 3 6}$ & 0,559 \\
\hline
\end{tabular}




\begin{tabular}{cccccc}
\hline OBAR3 & 0,547 & 0,511 & 0,666 & $\mathbf{0 , 9 3 1}$ & 0,521 \\
\hline eGVNSZ1 & 0,040 & 0,314 & 0,411 & 0,415 & $\mathbf{0 , 8 6 6}$ \\
\hline eGVNSZ2 & 0,003 & 0,347 & 0,476 & 0,504 & $\mathbf{0 , 9 1 7}$ \\
\hline eGVNSZ3 & 0,220 & 0,336 & 0,644 & 0,565 & $\mathbf{0 , 8 6 0}$ \\
\hline
\end{tabular}

Ayırt edici geçerliliğin ikinci aşaması ise çapraz yüklerdir. Her bir değişkene ait faktör yükleri ile çapraz yükler arasında en az 0,1'lik fark olması beklenmektedir. Bu durumda maddelerin binişik madde olmadığı ifade edilmektedir (Yıldız, 2020). Tablo 4'te de koyu renkli değerler değişkenlerin faktör yüklerdir. Diğer değeler ise çapraz yüklerdir. Tablo incelendiğinde çapraz yükler ile faktör yükleri arasında 0,1'den daha büyük farklar olduğu ve dolayısıyla da binişik madde olmadığı görülmektedir. Böylece ayırt edici geçerliliğin ikinci şartı da sağlanmış olmaktadır.

Tablo 5: HTMT Kriterine Göre Ayırt Edici Geçerlilik

\begin{tabular}{cccccc}
\hline & DVR & NYT & OAR & OBAR & e-GVNSZ \\
\hline DVR & & & & & \\
\hline NYT & 0,579 & & & & \\
\hline OAR & 0,542 & 0,519 & & & \\
\hline OBAR & 0,544 & 0,534 & 0,785 & & \\
\hline e-GVNSZ & 0,121 & 0,414 & 0,663 & 0,625 & \\
\hline
\end{tabular}

Ayırtedici geçerliliğin son aşaması ise HTMT (Heterotrait-Monotrait Ratio) kriteridir. Bu kritere ilişkin bilgiler de Tablo 5'teki gibidir. Bir görüşe göre HTMT katsayısı 0,9' dan küçük (Gold vd., 2001), bir başka görüşe göre ise HTMT katsayısı 0,85'den küçük (Kline, 2010) olmalıdır. Her iki görüşe göre de tablodaki değerler HTMT kriterini sağlamaktadır. Böylece ayırt edici geçerliliğin üç aşaması da sağlanmıştır.

\subsection{Yapısal Modelin Test Edilmesi}

Araştırma modelinin test edilmesinde kısmi en küçük kareler yöntemi (PLS-SEM) kullanılmıştır. SmartPLS istatistik paket programı aracılığıyla da analizler gerçekleştirilmiştir. Tablo 6 'da analiz sonuçlarını gösteren bulgular yer almaktadır.

Yeniden örnekleme yöntemi (Bootstrapping) ile 5000 alt örneklem seçilerek değişkenlerin etkileri ölçülmüştür. Buna göre, çevrimiçi alışverişin algılanan riskinin e-güvensizliği etkilediği $(\beta=0,383 ; p<0,000)$; çevrimiçi bilgi aramanın algılanan riskinin egüvensizliği etkilediği $(\beta=0,311 ; p<0,000)$; e-güvensizliğin webrooming niyetini etkilediği $(\beta=0,379 ; p<0,000)$ ve webrooming niyetinin webrooming davranışını etkilediği $(\beta=0,546 ; p<0,000)$ sonucuna ulaşılmıştır. Böylece $\mathrm{H}_{1 \mathrm{a}}, \mathrm{H}_{1 \mathrm{~b}}, \mathrm{H}_{2}$ ve $\mathrm{H}_{3}{ }^{\prime}$ ün desteklendiğini söylemek mümkünüdür.

Tablo 6: Yapısal Eşitlik Modeli Sonuçları

\begin{tabular}{|c|c|c|c|c|c|c|c|c|}
\hline \multicolumn{2}{|c|}{ Hipotezler } & \multirow{2}{*}{$\begin{array}{c}\text { Std. } \\
\text { Beta } \\
0,383 \\
\end{array}$} & \multirow{2}{*}{$\begin{array}{c}\text { Std. } \\
\text { Hata } \\
0,074 \\
\end{array}$} & \multirow{2}{*}{$\begin{array}{c}\text { t-Değerleri } \\
5,174 \\
\end{array}$} & \multirow{2}{*}{$\begin{array}{c}\mathbf{p} \\
0,000\end{array}$} & \multirow{2}{*}{$\begin{array}{c}\mathbf{f}^{2} \\
0,133 \\
\end{array}$} & \multirow{2}{*}{$\begin{array}{c}\text { VIF } \\
1,851\end{array}$} & \multirow{2}{*}{$\begin{array}{c}\text { Sonuç } \\
\text { Desteklend }\end{array}$} \\
\hline $\mathrm{H}_{1 \mathrm{a}}$ & e-GVNSZடOAR & & & & & & & \\
\hline $\mathrm{H}_{1 \mathrm{~b}}$ & e-GVNSZ $\leftarrow$ OBAR & 0,311 & 0,077 & 4,034 & 0,000 & 0,088 & 1,851 & Desteklendi \\
\hline $\mathrm{H}_{2}$ & NYT $<\mathrm{e}-$ GVNSZ & 0,379 & 0,067 & 5,633 & 0,000 & 0,167 & 1,000 & Desteklendi \\
\hline $\mathrm{H}_{3}$ & DVR $\leftarrow N Y T$ & 0,546 & 0,041 & 13,378 & 0,000 & 0,426 & 1,000 & Desteklendi \\
\hline
\end{tabular}

Regresyon katsayılarına bakıldığında, çevrimiçi alışverişin algılanan riski değişkeni için 0,776-0,905 arasında, çevrimiçi bilgi aramanın algılanan riski değişkeni için 0,931-0,955 arasında, e-güvensizlik değişkeni için 0,860-0,917 arasında, webrooming niyeti değişkeni için 0,937-0,964 arasında, webrooming davranışı değişkeni için ise 0,927-0,951 arasındadır.

Hair vd. (2011)'e göre $R^{2}$ değerlerinin 0,25 ve üzerinde olması zayıf seviyede, 0,50 ve üzerinde olması orta seviyede, 0,75 ve üzerinde olması ise yüksek seviyede açıklayıcılığı ifade etmektedir. Ancak bazı bilimsel çalışmalarda $\mathrm{R}^{2 \prime}$ nin $\% 10$ olarak hesaplanması da yeterli olacağı yönünde görüşler vardır (Yıldız, 2020). Modeldeki değişkenlerin $\mathrm{R}^{2}$ değerleri incelendiğinde de egüvensizliğin \%40,5 oranında açıklayıcılığının olduğu; webrooming niyetinin \%14,3 oranında açıklayıcılığının olduğu ve webrooming davranışının ise $\% 29,9$ oranında açıklayıcılığının olduğu tespit edilmiştir. 
Araştırma modelinin, $\mathrm{Q}^{2}$ değerlerinin (tahmin gücü katsayılarının) belirlenebilmesi için Blindfolding analizi çalıştırılmıştır. $\mathrm{Q}^{2}{ }^{\prime}$ nin sıfırdan büyük olması modelin endojen değişkenleri tahmin gücüne sahip olduğunu ifade etmektedir (Hair vd., 2014). Analiz sonucunda tespit edilen $Q^{2}$ değerleri e-güvensizlik için 0,299; webrooming niyeti için 0,125 ve webrooming davranışı için de $0,261^{\prime}$ dir. Böylelikle modelin değişkenleri tahmin gücüne sahip olduğu söylenebilir.

Bakılması gereken bir diğer gösterge de $\mathrm{f}^{2}$ (etki büyüklüğü/effect size) değerleridir. Tablo $6^{\prime}$ da bu değerler gösterilmiştir. Cohen (1992)'e göre $\mathrm{f}^{2}$ 'nin 0,02 ve üzerinde olması düşük, 0,15 ve üzerinde olması orta ve 0,35 ve üzerinde olması ise yüksek olarak değerlendirilir. Buna göre, çevrimiçi alışverişin algılanan riski $\left(f^{2}=0,133\right)$ ve çevrimiçi bilgi aramanın algılanan riski $\left(f^{2}=0,088\right)$ değişkenlerinin e-güvensizliği etkileme gücü düşüktür. e-Güvensizliğin webrooming niyetini etkileme gücü $\left(f^{2}=0,167\right)$ orta seviyedir. Webrooming niyetinin webrooming davranışını etkileme gücü $\left(f^{2}=0,426\right)$ ise yüksek seviyedir.

\section{Şekil 2: PLS Yapısal Eşitlik Sonuçları}

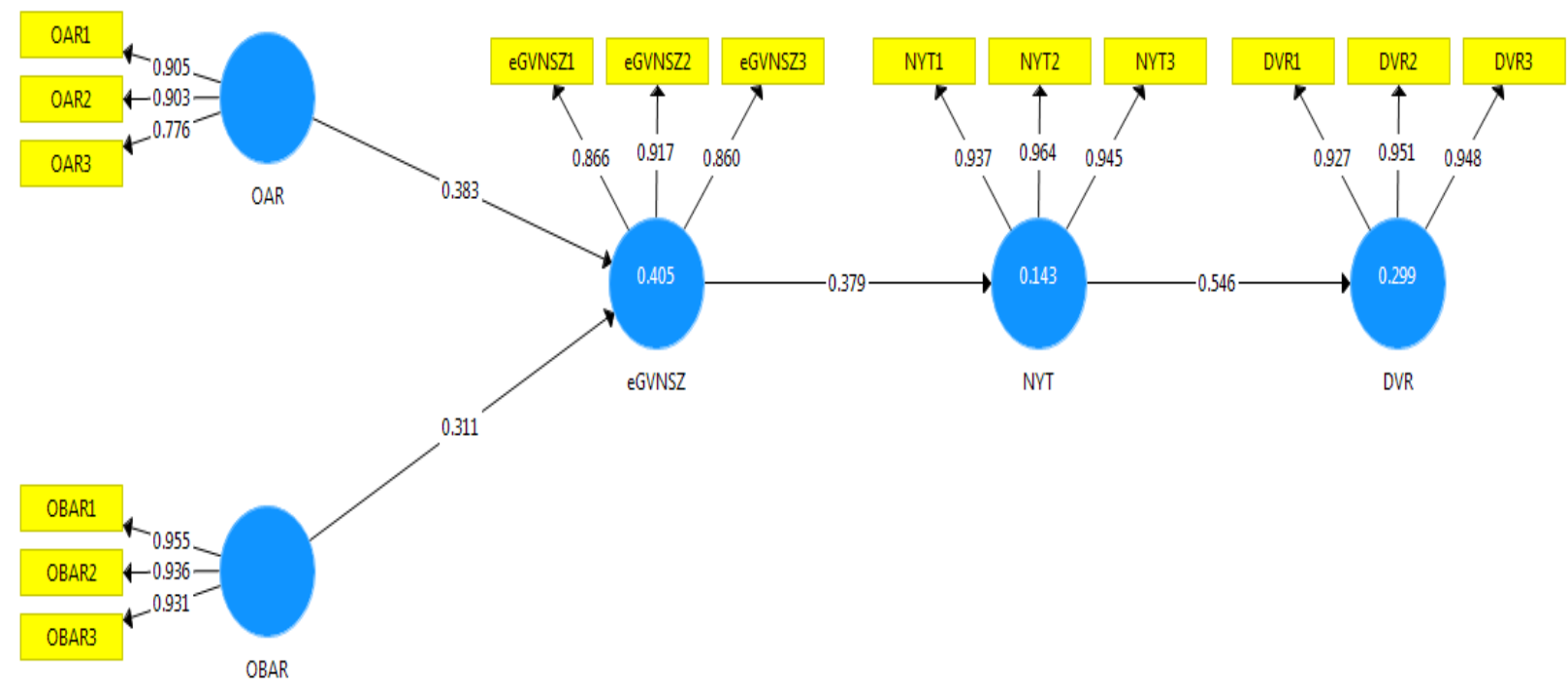

Ayrıca Tablo 6'da yer alan değerlerden biri de VIF (Variance Inflation Factor) değerleridir. SmartPLS programına göre VIF değerleri 3'ün altında olması gerekmektedir (Diamantopoulos ve Siguaw, 2006). Araştırmadaki değişkenlerin VIF değerleri de bu şartı sağladığından değişkenler arasında çoklu bağlantı probleminin olmadığını ifade etmek mümkündür.

\section{SONUÇ VE ÖNERILER}

Algılanan risk, 60’lı yıllardan beri tüketici davranışlarını anlamada sıklıkla üzerinde durulan kavramların başında gelmektedir. Çünkü ister çevrimdışı ister çevrimiçi kanallar olsun tüketiciler satın alma davranışı gösterirken çeşitli riskler algılamaktadırlar. Risk algısının yüksek oluşu ise güven sorununun ya da güvensizliğin olduğuna işaret eder. Bu çalışmanın amacı da, tüketicilerin çevrimiçi alışverişlerde algıladıkları bu riskin güvensizlik üzerindeki etkilerini, güvensizliğin de tüketiciyi ürünleri internetten araştırsa bile mağazadan satın almayı tercih etmesi olarak adlandırılan webroominge yönelik niyet ve davranışlar üzerindeki etkisini incelemektir. Bu bağlamda çevrimiçi anketler vasıtasıyla 211 katılımcıdan veri toplanmıştır. Webrooming davranışını inceleyen uluslararası literatürde hatrı sayılır sayıda çalışma olsa da Türkçe literatürde bu çalışmaların sayısının çok daha sınırlı olduğu söylenebilir. Dolayısıyla bu çalışmanın Türkçe literatüre hem webrooming davranışı konusunda hem de bu davranışın algılanan risk çerçevesinde incelenmesi konusunda katkı sağlayacağı söylenebilir.

Araştırma bulgularına göre çevrimiçi alışverişin algılanan riski ve çevrimiçi bilgi aramanın algılanan riski olarak iki boyutlu şekilde ele alınan algılanan riskin e-güvensizlik üzerinde pozitif etkisi olduğu sonucuna varılmıştır. Chou vd. (2016) ve Arora ve Sahney (2018)'in çalışmasında da benzer sonuçları görmek mümkündür. Gerekçeli Eylem Teorisi bağlamında da e- güvensizliğin webrooming niyeti üzerinde pozitif etkisi olduğu araştırmanın bir başka sonucudur. Bu sonucun Arora ve Sahney (2018)'in çalışması ile paralellik gösterdiğini söylemek mümkündür. Chou vd. (2016)'nin çalışmasında ise e-güvensizlik webrooming niyetini negatif olarak etkilemektedir. Oysaki çevrimiçi ortamlara güvensizlik hisseden bir tüketicinin bilgi arayışını internetten 
gerçekleştirerek mağazadan satın alma niyeti göstermesi daha olası bir sonuçtur. Dolayısıyla bu çalışmanın sonuçları, tüketicilerin e-işletmelere ve/veya e-satıcılara yönelik algıladıkları riskler ve güvensizlik sonucunda fiziksel mağazalardan satın alma gerçekleştirerek kendilerini koruma altına aldıklarını göstermektedir.

Araştırma sonuçlarının katkılarını iki şekilde değerlendirmek mümkündür. Bunlardan biri tüketici davranışları literatürüne olan katkıları, diğeri ise uygulamacılara olan katkılarıdır. Bu çalışma algılanan risk ve e-güvensizlik değişkenlerinin webrooming niyet ve davranışını nasıl etkilediğini bir modelle ortaya koyan Türkçe literatürdeki ender çalışmalardan biridir. Dolayısıyla Türkçe tüketici davranışları literatürüne sağlayacağı en önemli katkı bu boşluğu dolduracak olmasıdır. Tüketicilerin algıladıkları risk arttıkça çevrimiçi işletmelere olan güvensizlikleri de artacağından, öncelikle e-işletmelerin tüketicilerin algılanan alışveriş riskini azaltmalarını sağlayacak özellikle finansal, psikolojik ve teslimat gibi konularda güvenlerini artırıcı şekilde web sitelerini düzenlemeleri gerekmektedir. Ayrıca algılanan riskin bir başka boyutu olan algılanan bilgi arama riskine yönelik olarak da ürünler hakkında detaylı bilgiler ve ürün fotoğraflarını içerecek şekilde web sitelerini yeniden tasarlamaları gerekmektedir. Özellikle bu noktada ürünlerin boyutları, renkleri gerçeğe uygun şekilde görsellerle desteklenmelidir. Böylece çevrimiçi alışverişe yönelik algılanan risk düşeceğinden e-işletmeye ve/veya e-satıcıya olan güvensizlik de azalacaktır. Dolayısıyla tüketiciler bir ürünü internetten araştırarak başladıkları süreci internetten satın alarak sonuçlandırabileceklerdir. Ayrıca e-işletmelerin ve/veya esatıcıların tüketicilere çeşitli kampanyalar sunarak çevrimiçi alışverişin risklerini minimize edecek yönde algılamalarını sağlamalıdırlar.

Her araştırma gibi bu araştırmada belli kısıtlar altında gerçekleşmiştir. Verilerin toplanma aşamasında örnekleme yöntemi olarak olasılığa dayanmayan bir örnekleme yönteminin seçilmesi araştırmanın sonuçlarının genellenebilirliğine gölge düşürmektedir. Ayrıca araştırmada belirli bir ürün kategorisi üzerinden bir kurgu yapılmamış olup genel olarak tüketicileri webrooming davranışına yönelten risk ve güvensizlik üzerinde durulması da bir başka kısıtı oluşturmaktadır. Araştırmanın bir diğer kısıtı ise verilerin pandemi sürecinde toplanmış olmasıdır. Sonuçta birçok tüketici bu dönemde fiziksel ortamlardan alışveriş yapamamış veyahut çok kısıtlı yapabilmişlerdir. Ancak yine de çıkan sonuçlar bu süreç tüketicileri her ne kadar çevrimiçi alışverişe zorunlu olarak itse de normalleşmeyle birlikte tüketicilerin webrooming davranışlarını ilk etapta devam ettirecekleri söylenebilir.

Gelecek çalışmalarda özellikle belirli bir ürün grubuna yönelik olarak webrooming davranışı incelenebilir. Farklı ürün gruplarında bu davranış da farklı şekillerde tezahür edebilir. Araştırma modeli genişletilerek özellikle davranışsal kontrol değişkeni de modele dahil edilerek Planlı Davranış Teorisi bağlamında test edilebilir. Algılanan riskin çevrimiçi alışverişlerde önemi kadar bir başka önemli değişken de algılanan faydadır. Modele algılanan fayda değişkeni de eklenerek tüketicilerin webrooming niyet ve davranışını nasıl şekillendirdiği incelenebilir. Ayrıca webrooming konusunda daha derinlemesine bilgi edinebilmek açısından nitel yöntemler tercih edilerek de bir araştırma deseni de oluşturulabilir.

\section{KAYNAKÇA}

Akıncı, S. ve Kıymalığlu, A. (2014). Planlı Davranış Teorisi. içinde Pazarlama Teorileri, Ed: M. İ. Yağcı ve S. Çabuk, İstanbul: MediaCat Yayınları.

Ajzen, I. and Fishbein, M. (1980). Understanding attitudes and predicting social behavior. Englewood Cliffs, New Jersey: Prentice-Hall.

Arora, S., and Sahney, S. (2017). Webrooming behaviour: a conceptual framework. International Journal of Retail \& Distribution Management.

Arora, S., and Sahney, S. (2018). Consumer's webrooming conduct: an explanation using the theory of planned behavior. Asia Pacific Journal of Marketing and Logistics.

Aw, E. C. X. (2019). Understanding the webrooming phenomenon. International Journal of Retail \& Distribution Management. 47(10), $1074-1092$.

Aw, E. C. X. (2020). Understanding consumers' paths to webrooming: A complexity approach. Journal of Retailing and Consumer Services, 53, 101991.

Aw, E. C. X., Basha, N. K., Ng, S. I. and Ho, J. A. (2021). Searching online and buying offline: Understanding the role of channel-, consumer-, and product-related factors in determining webrooming intention. Journal of Retailing and Consumer Services, 58, 102328.

Balasubramanian, S., Raghunathan, R. and Mahajan, V. (2005). Consumers in a multichannel environment: Product utility, process utility, and channel choice. Journal of Interactive Marketing, 19(2), 12-30.

Bauer, R. (1967). Consumer Behavior and Risk Taking in Risk Taking and Information Handling in Consumer Behavior. Edited by: Donald F. Cox, Harvard University Press, USA. Bell, D., Cuthbertson, R. ve Koskinen, S., 2000.

Bauer, H. H., Barnes, S. J., Reichardt, T., and Neumann, M. M. (2005). Driving consumer acceptance of mobile marketing: A theoretical framework and empirical study. Journal of Electronic Commerce Research, 6(3), 181-192. 
Bhatnagar, A., Mirsa, S. and R.H. Rao (2000). On Risk, Convenience and Internet Shopping Behavior. Communications of the ACM, 43(11), 98-105. Bosman, J. (2011). Book shopping in stores, then buying online. The New York Times. 4th December.

Brynjolfsson, E., Hu, Y. J., and Rahman, M. S. (2013). Competing in the age of omnichannel retailing (pp. 1-7). Cambridge, MA: MIT.

Chang, Y. S., and Fang, S. R. (2013). Antecedents and distinctions between online trust and distrust: predicting high-and low-risk internet behaviors. Journal of Electronic Commerce Research, 14, 149-166.

Choi, H-S. and Yang, S-B. (2016). An Empirical Study on Influencing Factors of Switching Intention from Online Shopping to Webrooming. Intell Information System, 22(1), 19-41.

Chou, S.Y., Shen, G.C., Chiu, H.C. and Chou, Y.T. (2016). Multichannel service providers' strategy: understanding customers' switching and freeriding behavior, Journal of Business Research, 69 (6), 2226-2232.

Cohen, J. (1992). Statistical power analysis. Current directions in psychological science, 1(3), 98-101.

Compeau, D. R. and Higgins, C. A. (1995). Computer Self-Efficacy: Development of a Measure Initial Test. MIS Quarterly, $19(2): 189-211$.

Deloitte, 2014. https://www2.deloitte.com/tr/tr/pages/consumer-business/articles/understanding-consumer-behavior-shopping-trends.html, Erişim Tarihi: 10.02.2021.

Deloitte, 2017. Thanks Giving Pulse Survey. https://bit.ly/2IOKEg6, Erişim Tarihi: 10.02.2021.

Dholakia U.M., Kahn B.E., Reeves R, Ridfleisch A, Stewart D. and Taylor, E. 2010. Consumer behavior in multichannel, multimedia retailing environment. Journal of Interactive Marketing 24(2): 86-95.

Diamantopoulos, A. and Siguaw, J. A. (2006). Formative versus reflective indicators in organizational measure development: A comparison and empirical illustration. British journal of management, 17(4), 263-282.

Fernandez, N. V., Perez, M. J. S. and Vázquez-Casielles, R., (2018). Webroomers versus showroomers: Are they the same? Journal of Business Research, 92, 300-320.

Fishbein, M. and Ajzen, I. (1975). Belief, attitude, intention and behavior: an introduction to theory and research. Reading, MA: Addison-Wesley.

Flavian, C., Gurrea, R. and Orus. C. (2016). Choice confidence in the webrooming purchase process: The impact of online positive reviews and the motivation to touch. Journal of Consumer Behaviour, 15 (5):459-476.

Fornell C., and Larcker, D.F. (1981). Evaluating structural equation models with unobservable variables and measurement error. J Mark Res, 18(1), 39-50.

Forsythe, S.M. and Shi, B. (2003). Consumer Patronage and Risk Perceptions in Internet Shopping. Business Research, 56 (11), $867-875$.

Forsythe, S., Liu, C., Shannon, D. and Gardner, L. C. (2006). Development of a scale to measure the perceived benefits and risks of online shopping. Journal of interactive marketing, 20(2), 55-75.

Gensler, S., Verhoef, P.C. and Böhm, M., 2012. Understanding consumers' multichannel choices across the different stages of the buying process. Marketing Letters, 23 (4), 987-1003.

Gold, A. H., Malhotra, A., and Segars, A. H. (2001). Knowledge management: An organizational capabilities perspective. Journal of management information systems, 18(1), 185-214.

Gupta, S., Lehmann, D. R. and Stuart, J. A. (2004). Valuing customers. Journal of marketing research, 41(1), 7-18.

Ha, S. and Stoel, L. (2009). Consumer e-shopping acceptance: antecedents in a technology acceptance model. Journal of Business Research, 62 (5), 565-571.

Hair, Joseph F. and Ringle, C. M. (2011). PLS-SEM: Indeed a Silver Bullet. The Journal of Marketing Theory and Pratice, 19 , s. $139-152$.

Hair, Joseph F., G. Tomas M. Hult, Christian M. Ringle and Marko Sarstedt (2014). A Primer on Partial Least Square Structural Equations Modeling (PLS-SEM), Los Angeles: Sage.

Hassanein, K. and Head, M. (2005). The impact of infusing social presence in the web interface: an investigation across product types. International Journal of Electronic Commerce, 10 (2), 31-55.

Hassanein, K., Head, M. and Ju, C. (2009). A cross-cultural comparison of the impact of social presence on website trust, usefulness and enjoyment. International Journal of Electronic Business, 7 (6), 625-641.

Henseler, J., Hubona, G., and Ray, P. A. (2016). Using PLS path modeling in new technology research: updated guidelines. Industrial management \& data systems. 
Hong, I.B. and Cha, H.S. (2013). The mediating role of consumer trust in an online merchant in predicting purchase intention. International Journal of Information Management, 33 (6), 927-939.

Kim, D. J, Ferrin, D. L. and R.H. Rao (2008). A Trust Based Consumer Decision-Making Model in Electronic Commerce: The Role of Trust, Perceived Risk and Their Antecedents. Decision Support Systems, 44 (2), 544-564.

Kline, R. (2011). Principles and Practice of Structural Equation Modeling, Guilford Press, New York.

Kramer, R. M. (1999). Trust and distrust in organizations: emerging perspectives, enduring questions. Annual Review of Psychology, 50, 569-598.

Lee, M. K. and Turban, E. (2001). A trust model for consumer internet shopping. International Journal of electronic commerce, 6(1), 75-91.

Lee, K.S. and Tan, S. J. (2003). E-retailing Versus Physical Retailing: A Theoretical Model and Empirical Test of Consumer Choice. Journal of Business Research, 56(11), 877-885.

Lewicki, R. J. (2006). Trust and distrust. In: Schneider, A. K., \&Honeyman, C. (Eds.) The negotiator's fieldbook. Washington: American Bar Association, Section of Dispute Resolution. 191-202.

Manss, R., Kurze, K., and Bornschein, R. (2020). What drives competitive webrooming? The roles of channel and retailer aspects. The International Review of Retail, Distribution and Consumer Research, 30(3), 233-265.

McKnight, D.H., Kacmar, C.J. and Choudhury, V. (2004). Dispositional trust and distrust distinctions in predicting high-and low-risk internet expert advice site perceptions. E-Service Journal, 3 (2), 35-55.

Ogonowski, A., Montandon, A., Botha, E. and Reyneke, M. (2014). Should new online stores invest in social presence elements? The effect of social presence on initial trust formation. Journal of Retailing and Consumer Services, 21 (4), 482-491.

Olivero, N. and Lunt, P. (2004). Privacy versus willingness to disclose in e-commerce exchanges: the effect of risk awareness on the relative role of trust and control. Journal of Economic Psychology, 25 (2), 243-262.

Schröder, H., and Zaharia, S. (2008). Linking multi-channel customer behavior with shopping motives: An empirical investigation of a German retailer. Journal of Retailing and Consumer Services, 15(6), 452-468.

Shankar, A., and Jain, S. (2021). Factors affecting luxury consumers' webrooming intention: a moderated-mediation approach. Journal of Retailing and Consumer Services, 58, 102306.

Tan, S. J. (1999). Strategies for Reducing Consumers' Risk Aversion in Internet shopping. The Journal of Consumer Marketing, $16(2), 163-178$.

Tan, F.B. and Sutherland, P. (2004). Online consumer trust: a multi-dimensional model. Journal of Electronic Commerce in Organizations, 2 (3), 4058.

Taylor, J. W. (1974). The Role of Risk in Consumer Behavior. Journal of Marketing,38 (2), 54-60.

Uygun, M., Özçifçi, V. and Divanoğlu, S. U. (2011). Tüketicilerin online alışveriş davranışını etkileyen faktörler. Organizasyon ve Yönetim Bilimleri Dergisi, 3(2), 373-385.

Verhoef, P. C., S. A. Neslin, and B. Vroomen (2007). Multichannel customer management: Understanding the research-shopper phenomenon. International Journal of Research in Marketing 24 (2):129-148.

Wolny, J. and Charoensuksai, N. (2014). Mapping customer journeys in multichannel decision-making. Journal of Direct, Data and Digital Marketing Practice, 15(4), 317-326.

Yıldız, E. (2020). SmartPLS ile Yapısal Eşitlik Modellemesi. Seçkin Yayıncılık. 